Int. J. Electrochem. Sci., 11 (2016) 9928 - 9940

\title{
An All-Solid-State Ammonium Ion-Selective Electrode Based on Polyaniline as Transducer and Poly (o-phenylenediamine) as Sensitive Membrane
}

\author{
Yating Kan ${ }^{l}$, Chenhua Han ${ }^{2, *}$, Ying Y $e^{l}$, Xiao Zhang ${ }^{l}$, Yuanfeng Huang ${ }^{l}$, Liang Xing ${ }^{l}$, Yifan Zhou , \\ Huawei Qin ${ }^{3}$ \\ ${ }^{1}$ Ocean College, Zhejiang University, Zhoushan 316021, China \\ ${ }^{2}$ Laboratory of Marine Ecosystem and Biogeochemistry, Second Institute of Oceanography, State \\ Oceanic Administration, Hangzhou 310012, China \\ ${ }^{3}$ School of Mechanical Engineering, Hangzhou Dianzi University, Hangzhou 310018, China \\ *E-mail: hanchenhua@sio.org.cn
}

doi: $10.20964 / 2016.12 .03$

Received: 21 August 2016 / Accepted: 29 September 2016 / Published: 10 November 2016

An all-solid-state ammonium ion-selective electrode, with silver/nano-silver wire as the substrate, polyaniline as transducer and poly (o-phenylenediamine) as sensitive membrane, is presented. The nano-silver was prepared by electrodeposition in $0.1 \mathrm{M} \mathrm{AgNO}_{3}$ standard solution with the half-sine wave at amplitude of $500 \mathrm{mV}$, frequency of $50 \mathrm{HZ}$ and action time of $1 \mathrm{~min}$. The polyaniline and poly (o-phenylenediamine) were electropolymerized on the surface of the silver/nano-silver substrate by cyclic voltammetry with the scanning potential from 0 to $0.45 \mathrm{~V}$ in solutions of $1.0 \mathrm{M}$ aniline hydrochloride and $0.08 \mathrm{M}$ o-phenylenediamine hydrochloride, respectively. Under the SEM, poly (ophenylenediamine) with 0.5-5 $\mu \mathrm{m}$ in size was evenly and firmly embedded on the surface of the PANI. This ammonium electrode exhibited low impedance of approximately $70 \mathrm{Ohm}$. It can detect as low as $1.2 \times 10^{-5} \mathrm{M}$ of ammonium ion, with the slopes of $54.99-55.70 \mathrm{mV}$ per decade $\left(\mathrm{R}^{2}>0.99\right)$ within a linear range between $2 \times 10^{-5} \mathrm{M}$ to $0.1 \mathrm{M}$. It responds as quickly as $0.5-2 \mathrm{~s}$, as well as its lifespan extends to at least 147 days. The electrode showed a superior selectivity toward $\mathrm{NH}_{4}{ }^{+}$, and was successfully applied to detect the $\mathrm{NH}_{4}{ }^{+}$concentration in real samples. In addition, this electrode is miniature and convenient for package and assembly, which will enable in-situ measurement and long-term monitoring of $\mathrm{NH}_{4}{ }^{+}$ concentration in rivers, lakes and industrial sewage.

Keywords: All-solid-state ammonium electrode; Low impedance; In-situ detection and longtime monitoring; Poly (o-phenylenediamine); Polyaniline

\section{$\underline{\text { FULL TEXT }}$}


(C) 2016 The Authors. Published by ESG (www.electrochemsci.org). This article is an open access article distributed under the terms and conditions of the Creative Commons Attribution license (http://creativecommons.org/licenses/by/4.0/). 